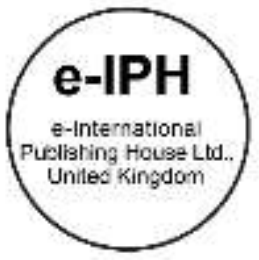

\title{
Investigating Space Use Patterns in a Malaysian Hospital Courtyard Garden: Lessons from real-time observation of patients, staff and visitors
}

\author{
Madihah Mat Idris, Magda Sibley, Karim Hadjri \\ School of Architecture, Faculty of Social Science, \\ University of Sheffield, Sheffield, United Kingdom \\ mimadihah1@sheffield.ac.uk,magda.sibley@sheffield.ac.uk,khadjri@sheffield.ac.uk \\ Tel : +447565208284
}

\begin{abstract}
This paper examines the behaviour of users of a large central courtyard in a hospital with the aim to develop an understanding of the activities and the space use patterns of patients, staff and visitors. Video-based and direct observation, as well as behaviour mapping, were employed to investigate how different types of users interact with the courtyard garden. This study reveals that significant differences existed in the way different user groups utilised the courtyard garden on a daily basis and this was found to be highly influenced by the physical environment, the hospital opening hours and the courtyard micro-climate.
\end{abstract}

Keywords: Observation; space use patterns; courtyard garden; hospital.

eISSN: 2398-4287 @ 2018. The Authors. Published for AMER ABRA cE-Bs by e-International Publishing House, Ltd., UK. This is an open access article under the CC BYNC-ND license (http://creativecommons.org/licenses/by-nc-nd/4.0/). Peer-review under responsibility of AMER (Association of Malaysian Environment-Behaviour Researchers), ABRA (Association of Behavioural Researchers on Asians) and cE-Bs (Centre for Environment-Behaviour Studies), Faculty of Architecture, Planning \& Surveying, Universiti Teknologi MARA, Malaysia.

DOI: https://doi.org/10.21834/e-bpj.v3i8.1413

\subsection{Introduction}

Courtyard gardens have become an important feature in the design and planning of hospitals as they not only allow for natural ventilation and daylighting but can also have a positive effect on the well-being of hospital users' through re-establishing peoples' interaction with nature. The courtyard garden is a common feature incorporated in the planning of many hospitals in Malaysia (Almhafdy et al., 2013a). As early as the 1970s in Malaysia, different types of courtyards were incorporated in the planning of hospitals. In 1998, the Malaysian Health Minister suggested that all government hospitals should include a garden in their planning and design (Shukor, 2007). However, even today there are no specific guidelines for the design of these courtyards and no research has been conducted so far on how different types of courtyard garden are currently performed and used in Malaysian hospitals.

This paper is based on an ongoing $\mathrm{PhD}$ study carrying out a post-occupancy evaluation of courtyard design in three case-studies of Malaysian hospitals. Further, this paper presents some of the initial results of fieldwork carried out in Malaysia in 2017/18 on the role of courtyards in one of the hospitals examined (case study $\mathrm{H} 1$ hospital). As part of the post-occupancy evaluation process, it is crucial on the part for the researcher to understand the perspective of the users of the occupied setting on how they use and interact with the

eISSN: 2398-4287 @ 2018. The Authors. Published for AMER ABRA cE-Bs by e-International Publishing House, Ltd., UK. This is an open access article under the CC BYNC-ND license (http://creativecommons.org/licenses/by-nc-nd/4.0/). Peer-review under responsibility of AMER (Association of Malaysian Environment-Behaviour Researchers), ABRA (Association of Behavioural Researchers on Asians) and cE-Bs (Centre for Environment-Behaviour Studies), Faculty of Architecture, Planning \& Surveying, Universiti Teknologi MARA, Malaysia.

DOI: https://doi.org/10.21834/e-bpj.v3i8.1413 
places. The behaviour of the users of a large central courtyard in $\mathrm{H} 1$ hospital was observed and recorded with the aim to develop an understanding of the activities and the space use patterns of different users in the courtyard garden of the hospital.

\subsection{Literature Review}

\subsection{Limitation of studies on courtyard design in Malaysian hospitals}

There have been very few studies conducted in courtyard buildings in hot humid climates as found typically in Malaysia. Some studies focused on residential buildings (Sadafi et al., 2012; Jamaludin, Hussein and Md.Tahir, 2016; Kubota et al., 2017) and educational buildings (Makaremi et al., 2012). Very little studies have focused on the hospital building (Sh. Ahmad et al.,2007 and Aripin, 2007; Almhafdy et al., 2013a). Although studies by Sh. Ahmad et al. (2007) and Aripin (2007) were conducted in a courtyard hospital, these studies did not specifically focus on the perception of users in the outdoor area (i.e. the courtyard garden) of the hospital. Instead, the emphasis of such studies was more on the perception of users on the daylighting particularly in the indoor area (i.e. ward area). Studies by Said (2003) and Ghazali and Abbas (2012) focused specifically on paediatric patients in the hospital and did not focus on how different types of courtyard users namely patients, staff and visitors used and interacted with the outdoor environment of a general type hospital.

While studies focused on the use of hospital outdoor gardens (i.e. rooftop garden, courtyard garden) have been widely conducted in other countries of a different climatic context (Cooper Marcus and Barnes, 1995; Paine, 1984; Shukor, 2012), an in-depth study on how different types of users used and perceived the different types of hospital courtyard gardens in Malaysia have not yet been systematically studied, thus ignoring the Malaysian hot humid climatic. There is no study that focuses specifically on different types of courtyard gardens in Malaysian hospitals. To date, only one study was found (i.e. Almhafdy et al., 2014) that focused on improving the microclimatic condition of courtyard design in a case study hospital in Malaysian hot and humid climate. Almhafdy et al. (2013b) studied several parameters to improve the microclimatic conditions of the courtyard in hospital buildings based on an environmental simulation study. In the context of a hospital building in a hot humid climate, this study highlighted the main issue of the courtyard garden which is improper consideration of the basic courtyard design criteria (i.e. the orientation, height and forms) resulting in uncomfortable courtyard conditions due to minimal shade, reduced airflow and higher temperature in the courtyard space and considerably contributes to the heat build-up inside the adjacent spaces (Almhafdy et al., 2014). Almhafdy et al. (2014) also highlighted that a semi-enclosed type (Ushape) courtyard garden provides better ventilation and a lower temperature compared to an enclosed type (0-shape) courtyard garden in the case study hospital. However, it can be argued that this study was limited to small sized enclosed courtyard garden ( 0 -shape) and thus, did not examine a larger type of enclosed courtyard garden (O-shape) such as the case study of $\mathrm{H} 1$ hospital presented in the research. In addition, a systematic evaluation on how the behaviour of different types of users in different types of courtyard design in hospitals influenced by the courtyard micro-climate (i.e. temperature, air humidity and wind speed) were not addressed in detail in the previous study by Almhafdy et al. (2014). Therefore, this study is pertinent to be conducted in order to investigate how the physical environment, the hospital opening hours and the microclimatic conditions of the courtyard garden influences the behaviour of different types of courtyard users in a case study hospital.

\subsection{Courtyard gardens in hospitals and their benefit to different types of users}

Spending long hours in a hospital can be a stressful experience for patients, staff and visitors (Cooper Marcus and Francis, 1998). Thus, having access to natural settings in the hospital buildings can improve health and the ability to cope with stress (Cooper Marcus, 2007). In a previous study, Cooper Marcus and Barnes (1995) found that outdoor gardens such as courtyard gardens in healthcare settings were commonly utilised by three distinct types of users namely the patients, the staff and the visitors. Earlier, Paine (1984) conducted observations at three different hospitals and revealed that of the three distinct types of users, staff utilised the outdoor space the most, either alone or in groups, visitors who accompanied the patients used the space the second most, followed by the alone patients who used the space the least (Cooper Marcus and Francis, 1998).

The ability of patients to go outdoor is determined by their health condition. Patients who have the ability to walk and who are not attached to monitoring equipment, as well as long-term care patients, are most likely to use the outdoor space (Cooper Marcus and Francis, 1998). However, it is also important to note that besides being in the garden, bedridden patients also can benefit from viewing the garden through the window (Ulrich, 1984; Verderber and Reuman, 1987). An observation conducted at the courtyard garden in a medical centre in California found that paediatric patients played in the children's maze provided in the courtyard area while waiting for their pediatric appointments: this provided them with an opportunity for respite from the painful and stressful time of being hospitalised (Cooper Marcus and Barnes, 1995).

In contrast to patients, staff are the most frequent users of hospital courtyards as staff collectively spend 24 hours working in the hospital environment to provide service and care to the patients Thus, they need a space such as an outdoor garden to enable them to escape from their daily routine and take breaks in a natural setting. A pre-post occupancy study of the preference and usage of courtyard gardens in hospital buildings conducted among nurses revealed that the majority of the nurses felt that it was important to them to be in outdoor spaces; furthermore, they were most likely to go outside alone and used the courtyard as a place for privacy (Naderi and Shin, 2008).

Although patients and staff are the main building occupants in hospitals and therefore spent the longest time in hospitals compared to visitors, the latter group are also hospital users who require access to the outdoor garden as a place to relieve their stress while waiting for their families who were either hospitalised or attending a medical appointment as an outpatient. In addition, Toone (2008) conducted a study in the courtyard of the Dell Children's Hospital in Austin, Texas. In this study, Toone determined that parents and family members of sick children experienced reduced stress levels after spending time in the courtyard garden while enjoying the view 
of nature instead of sitting and waiting in the interior spaces of the hospital. Moreover, the opportunity to receive visits from family members and colleagues is important for most patients (Cooper Marcus and Francis, 1998). Patients' rooms are often too small and do not have enough space for visitors and family to gather in comfort. Therefore, an outdoor garden such as courtyard garden is an essential place promoting social interaction for patients and visitors as well as staff.

\subsection{Behavioural observation}

Behavioural observation is widely used in the field of environment and behaviour research in order to develop an understanding of the interaction of people with physical settings. In a previous study, Betchel et al. (1987) highlighted the importance having a clear insight on the purpose of behavioural mapping, in which the researcher should record users' space use and behaviour onto a map to ensure that the patterns and frequency of behaviours could be related to the characteristic of the particular sites. In another study consisting of a post occupancy evaluation, behaviour mapping was considered as a comprehensive and systematic technique to explore how people interact with the characteristic of the design setting (Cooper Marcus, 1998). They also highlighted the need to accurately record and map the location of the behaviour of the people on the map of the study site and to pay attention to the date, time, weather and social interaction that occurred on site. In other previous literature, Whyte and Whyte (1984) highlighted the importance of mapping the physical and social scene in carrying out observational studies as it trains the researcher to become better at focusing on the details of the ongoing activities which will eventually provide a better understanding of the social relations within the scene.

In general, an effective behavioural observation requires the researcher to have skills to attend to details and an impeccable memory capacity that is necessary in taking note of the physical arrangement of the physical site and the overall activities happening within the spaces such as the occurrences of specific activities, the movement of people in a scene as well as people's interactions within the site (Goličnik and Ward Thompson, 2010). Nonetheless, in some cases, memorising and recording multiple activities that occur at the same time can be quite a challenge for the researcher and are often impossible to be done perfectly. Several researchers have previously used a diverse range of tools to facilitate recording people's activities and interaction on site via video recording, followed by activity mapping in order to develop a better and inclusive design (Whyte, 1980; Gehl, 1987; Cooper Marcus and Francis, 1998). Cooper Marcus and Barnes (1998) highlighted that several activities can be missed out during behavioural observation because of the time fluctuation of the activities that occurred at the observation sites that could not be captured by the researchers. Therefore, video-based field observation is an effective solution to collect the data of ongoing interactions between people and settings in a specific context. This overcomes the limitation imposed by self-observation and therefore minimises the numbers of unrecorded activities. Furthermore, the solution of using video recording as a tool in conducting an observation of a particular scene also brings several advantages (Jewitt, 2012, pp.5-8). Regarding durability, video data can be kept over a period, can repeatedly be viewed and the data can be revisited for further use and analysis in the future. This feature of data reviewing thus allows the researcher to observe any other activities and details that may have been missed during the fieldwork observation.

\subsection{Ethical consideration of the observational study in a hospital setting}

\subsubsection{Ethical approval and consent from the local authorities}

This study received ethical approval from both the School of Architecture's Ethics Committee, University of Sheffield and the Research \& Ethics Committee (MREC), Ministry of Health Malaysia prior to commencement of the fieldwork study in the case study hospitals in Malaysia. In addition, consent and permission for access from the director of each case study hospital were also obtained before the fieldwork were carried out.

\subsubsection{The right of the participants to be informed about the study}

It is crucial to raise awareness amongst the community of the study setting regarding the purpose of the researchers' presence, which is to observe and document their activities (Kawulich, 2005; Watts, 2011). In the case of a participant observation study conducted in a large public space such as the courtyard garden of Hospital $\mathrm{H} 1$, it would not be possible to gain informed consent from everyone who was photographed and filmed during the fieldwork. In such cases, the School of Architectures' ethics committee suggested that it is more appropriate if a researcher could place a prominent notice advising the participants on site about an observational study taking place. Following this guidance, in the present study a poster notice was used to inform users about the observational study taking place in the courtyard garden of the hospital so that they could understand that they were being observed for research purposes and that their images would be blurred and unidentifiable in order to protect their identity before being used in any future academic reports and presentations.

\subsubsection{Consent from the participants}

During the video-based observation, another fieldwork activity undertaken in the courtyard garden was a survey. The participants (the users of the courtyard garden) were informed about the nature of the study using the participant information sheet and they were asked to sign the consent form before taking part in the study. The content in the consent form clearly explained the nature of the activities in which they would participate, including completing the survey and being observed and filmed as part of the study. For example, some of the content in the consent form provided to the participant during the fieldwork included:

- $\quad$ "I understand that I had been filmed for the purpose of the observational study. I also agreed that my image in the video will be blurred and will not be identifiable by other people". 
- "I agree for the data including the survey data collected from me and the video recording of the observation on the users of the courtyard in this hospital to be used in future research and conference presentation".

\subsubsection{Anonymity and data confidentiality}

Crow and Wiles (2008) and Wiles et al. (2008) highlighted the importance of anonymity and confidentiality of the participants in social research. In particular, the researcher should make every possible effort to ensure data related to the participant such as visual data (images of the participants) could not be traced back to them in any form of subsequent dissemination including reports and presentations. For this present study, several measures were taken by the researcher to ensure that the anonymity and data confidentiality of the people who being observed was protected. This was done, for example by locating the video camera at a certain distance and adjusting the filming angle to avoid recording any user's identifiable images to preserve the identity of the participants. It is important to note that, all the data would be kept anonymous, and that the still images would be blurred for the purpose of dissemination either in reports or presentations.

\subsection{Design Methods}

\subsection{Site study}

Three $20^{\text {th }}$ century hospitals were selected as the case studies for the PhD research, namely $\mathrm{H} 1$ (a central large courtyard), $\mathrm{H} 2$ (an interlinked type courtyard) and $\mathrm{H} 3$ (a clustered type courtyard). These hospitals were selected as they comprised a representative sample of hospitals of a different design and configuration accessible for all types of users. As stated previously, this paper will only focus on one of the case study hospitals, designated $\mathrm{H} 1$ hospital.

The H1 hospital, located in the south part of Peninsular Malaysia, is a general specialist hospital complex that incorporates a large enclosed type of courtyard garden situated at the core of the hospital complex. This hospital complex was completed in 2004, comprising 10 floor levels that could accommodate 704 beds at any single time. The courtyard garden is approximately $2100 \mathrm{sqm}(70 \mathrm{~m} \times 30 \mathrm{~m})$, with about 70 percent of the area being planted with large canopy trees, herbal medicinal plants, shrubs and grass. Some of the striking landscape features include pergola walkways and a pergola-covered sitting area that offers protection from direct sunlight.

A diverse range and choice of sitting areas were provided to allow a social setting arrangement for either individuals or groups (see Figure 1). The H1 courtyard garden is located on level 2 of the hospital complex and bounded by the corridor serving as the main hospital street of the building complex which is accessible for all types of users. The courtyard is surrounded by an open corridor that allows the breeze into the surrounding indoor area. In addition, the glass walls of the cafeteria offer a visual transparency to the hospital courtyard garden, permitting interaction between both the indoor and outdoor areas. The design of the hospital street running along the boundary of the courtyard garden provides not only a physical access to the courtyard at Level 2 but also visual access to the garden from the other floor levels, as well as from the bridge on level 3 that is suspended above and across the courtyard garden (see Figure 2).

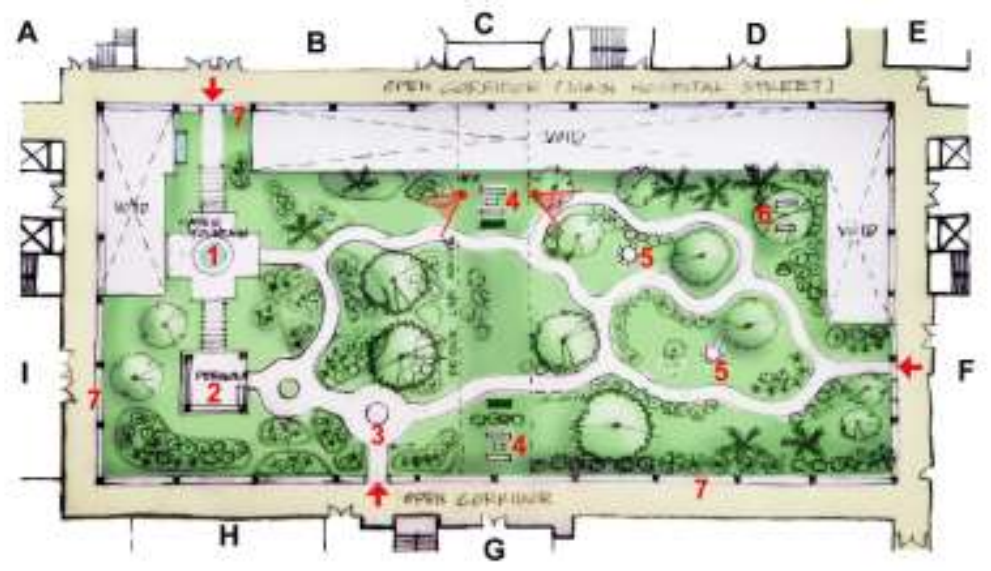

\section{LEGEND}

A-Specialist clinic B-Cafetaria

C-Auditorium

D. Education Centre

E-Accident and Emergency

Department

F. Imaging Departmetnt

G. Clinical Research Centre

$\mathrm{H}$ - Visitors rest house

1. MaE

4 Entrance

Location of the

Location of the
video camera.
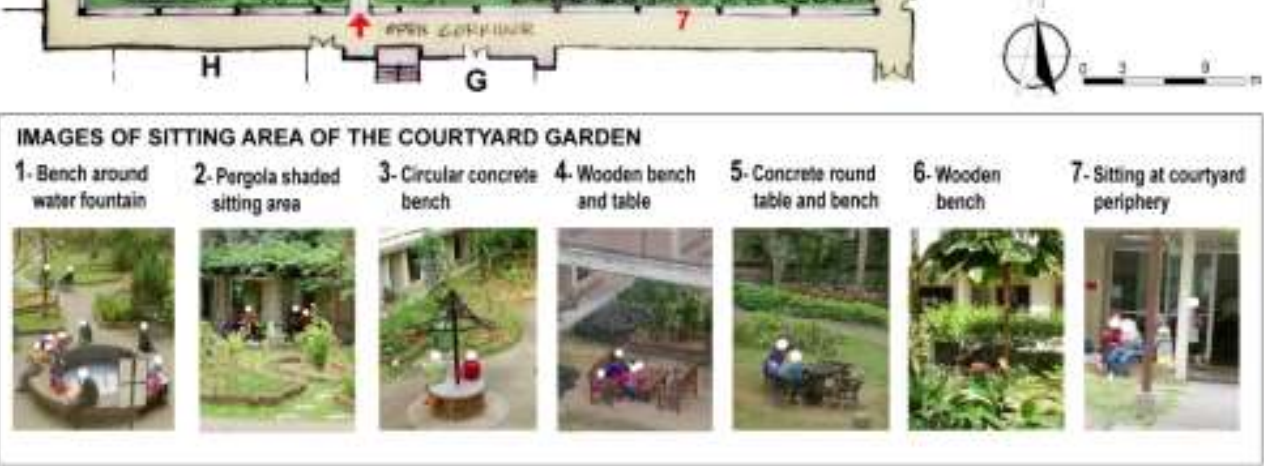

Fig. 1. Site map of the courtyard garden of the $\mathrm{H} 1$ hospital.

(Source: Sketch and photos by Author, 2018) 

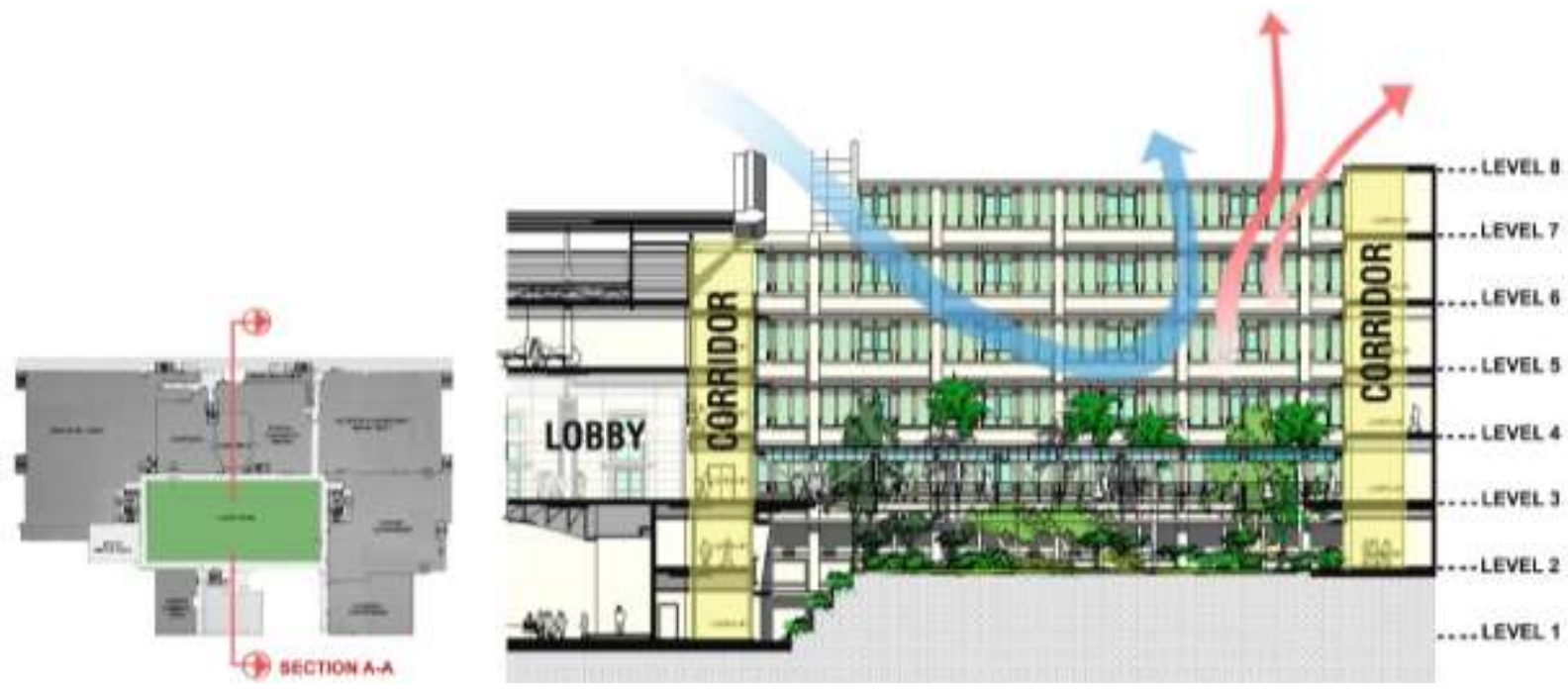

Fig. 2. Section A-A of the courtyard garden of the $\mathrm{H} 1$ hospital.

(Source: H1 Architects. Sdn. Bhd, re-illustrated by Author 2018)

\subsection{Data collection}

Prior to conducting the fieldwork, approval from the Malaysian Ministry of Health and the director of $\mathrm{H} 1 \mathrm{hospital}$ was obtained. The fieldwork took place in March 2018 from 5/3/2018 until 10/3/2018. Several fieldwork activities, including participant observation, field investigation, field measurement and surveys were undertaken during the whole week as part of a post occupancy evaluation study on courtyard design in Malaysian hospitals. This paper discusses one of the methods employed in the ongoing PhD study which is behavioural observation. It is crucial to note that the aim of this observation is to investigate the activities of the users (patients, staff and visitors) and to scrutinise the space use pattern in the courtyard garden of the $\mathrm{H} 1$ hospital. For the purpose of this study, the behavioural observation was carried out via a combination of two methods of observation: video-based observations; and direct observations. Eight hours of users' observation was conducted during a total period of 32 hours during two weekdays and two weekend days. The courtyard garden of the hospital was observed for a period of 8 hours per day ( $9 \mathrm{am}$ to $5 \mathrm{pm}$ ) during four consecutive days.

\subsubsection{Video-based observation and direct observation}

A site visit to the courtyard garden of the hospital was conducted before the video-based observation were carried out to become acquainted with the site topography and the layout of the courtyard garden, the on-site activities as well as any potential barriers on site that might affect the recording. It is important to note due to the limitation numbers of the observers and a large size of the courtyards (2100 sqm) with a multiple activity occurred at the same time, a video camera was used as a tool for the researcher to record the ongoing activities occurred on site. For this study, direct observation and mapping of the hidden activities (out of the video camera coverage area) were carried out simultaneous to the video recording. Two video cameras fixed on tripods (Camera A and Camera B) were set to run simultaneously for a total of 8 hours (the observation period) carried out during the day. Further, each camera covered a different area of the courtyard (East and West side of the courtyard garden) as illustrated in Figure 3. A trained research assistant was hired to monitor these video cameras during the days of observation to ensure the continuity and functionality of the video recording and the safety of the equipment. This included changing the battery of the video camera every two hours and transferring the video data onto file (categorised into four different recording time periods) (see Figure 4).

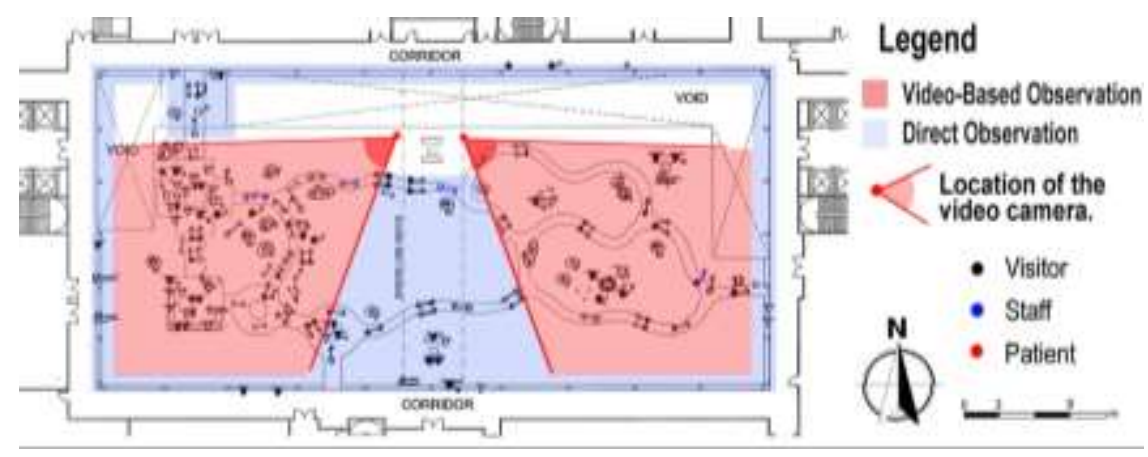

Fig. 3. The area of observation which is covered by a video recording and a direct observation.

Conducting a video recording was very useful in capturing multiple activities that occurred over a similar time period, thereby minimising the number of unrecorded activities if a direct observation were conducted on its own for such a study. Nevertheless, videobased observation has its drawbacks such as the limitation of the equipment including the number of available video cameras and the 
size of the camera lens. Moreover, some other barriers in the courtyard garden such as trees, shrubs and a big column of the bridge could also hinder recording all the activities that occurred behind such barriers. Therefore, to overcome the limitations of video recording, direct observation was carried out at the place out of the coverage of the video camera such as the periphery of the courtyard garden and the middle part of the courtyard that were blocked from the camera by the large bridge column and some plantings. This dual approach of video-based observation and direct observation were employed to ensure that this study was able to capture a rich and comprehensive data set.

\subsubsection{Behaviour mapping}

Observation and behaviour mapping are well-established techniques that are useful in the environment-behaviour research field to understand the interaction of human behaviour with the physical environment (Ittelson et al., 1970). For this study, a direct observation and mapping activity of the hidden activities (out of the video camera coverage area) were conducted concurrently during the video recording of users' activities in the hospital courtyard garden. During the video recording, the researcher would walk around the courtyard to observe the ongoing activities that are outside the coverage of the video camera. Those activities were observed directly on-site by the researcher were then mapped and categorised into four different time periods: 9 am - $11 \mathrm{am} ; 11 \mathrm{am}-1 \mathrm{pm} ; 1 \mathrm{pm}-3 \mathrm{pm}$; and 3 pm - $5 \mathrm{pm}$ (see Figure 4). During the direct observation period, each type of activity observed was mapped onto a floorplan of the courtyard garden of the hospital using different symbols as shown in Figure 5. Following this, the data from the video recording were then mapped onto a similar floor plan, completing the observation of the whole area of the site (see Figure 4).

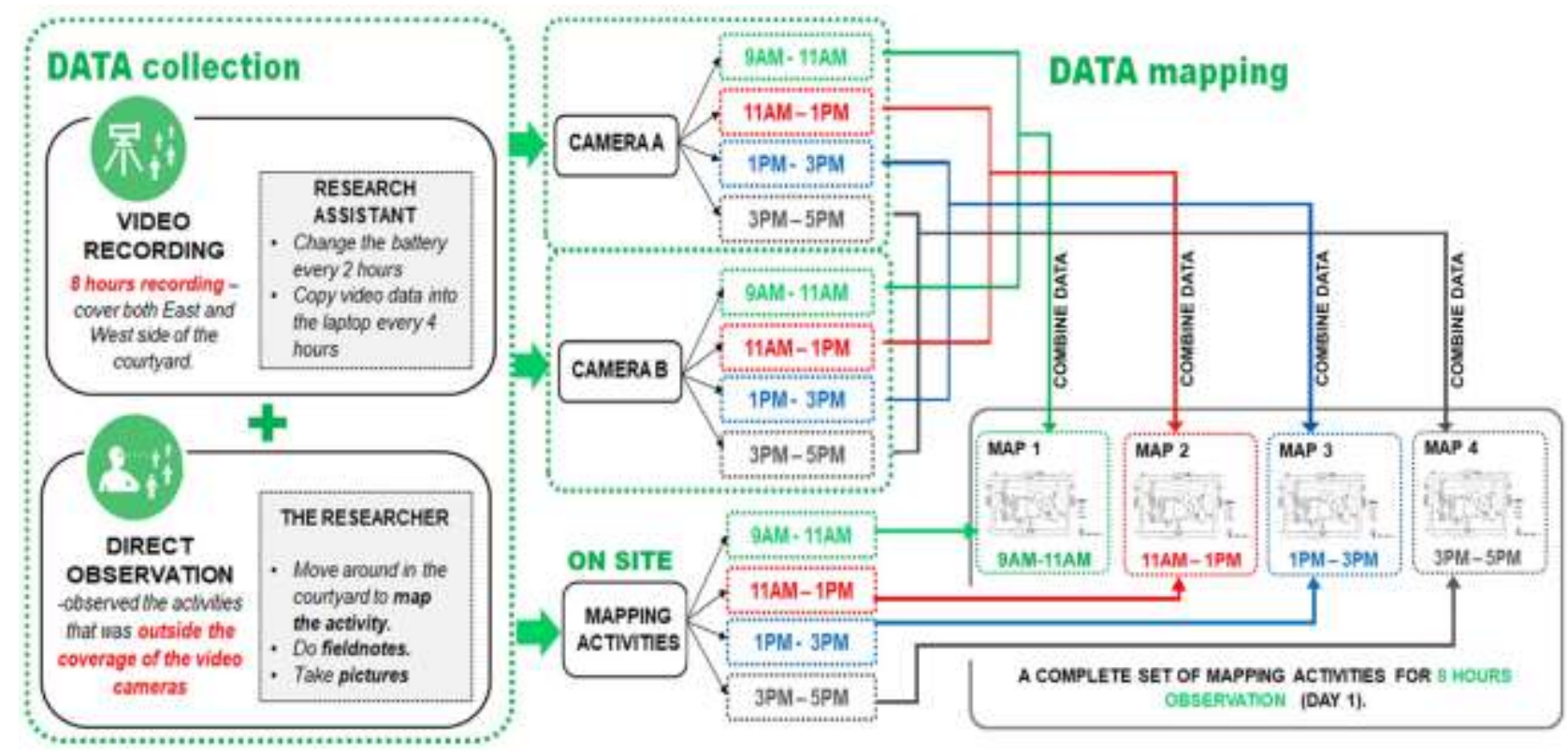

Fig. 4. The process of data collection and data mapping of 8 hours observation per day

For mapping activities, the table of activities developed by Goličnik and Ward Thompson (2010) was adopted and amended to suit the context of this study and the actual on-site activities. Each symbol that has been modified is illustrated in Table 1.

Table 1. Graphical symbols (m: male, f: female) used in behaviour mapping to indicate all types of activity at hospital courtyard.

\begin{tabular}{|c|c|c|c|c|c|c|c|c|}
\hline $\mathbf{m}$ & f & Activity & $\mathrm{m}$ & $f$ & Activity & m & f & Activity \\
\hline 0 & $\mathbf{v}$ & 1. Sitting & ars & -24 & 11. Walking around & $\alpha$ & $\alpha$ & 21. Standing - talking \\
\hline T & $\nabla$ & 2. Sitting on a bench & $0 \rightarrow$ & $\leftrightarrow$ & 12. Walking-pass through & $a_{*}$ & $a$ & 22. Standing and use a phone \\
\hline Q & ( & 3. Sitting around a table & $\stackrel{\leftrightarrow}{\infty}$ & $\stackrel{\phi}{\leftrightarrow}$ & 13. Walking with a child & 8 & \&े & 23. Standing and holding a baby \\
\hline प. & $\overline{6}$ & 4. Sitting and use a phone & $\sigma$ & 6 & 14. Walking and holding a baby & 0 & $=$ & 24. Laying down on a bench \\
\hline$\tau_{2}$ & $\mathbf{w}$ & 5. Sitting and sleeping on a bench & 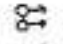 & $\vec{s}$ & 15. Walking in pair & 0 & 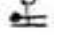 & 25. Laying down under the tree \\
\hline पण & च & 6. Sitting in pair & $\stackrel{g}{\circ}$ & 常 & 16. Walking in group & 吅 & $\bullet$ & 26. Reading book / newspaper \\
\hline 8 & (6) & 7. Sitting in the group (>2 people) & 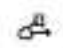 & 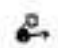 & 17. Walking with a pram & ß. & e. & 27. Eating and/or drinking \\
\hline II & t) & 8. Sitting on a wheelchair & $\sigma$ & $\Leftrightarrow$ & 18. Walking and use a phone & (6) & (9) & 28. Playing \\
\hline$\overline{\pi_{0}}$ & ד. & 9. Sitting and holding a baby & of & $\bullet$ & 19. Walking with a wheelchair user & 6 & 6 & 29. Playing in pair \\
\hline$U^{5}$ & $\nabla$ & 10. Sitting with a child & 0 & e & 20. Standing - Look around & ळ0 & (6) & 30. Playing in the group ( $>2$ people) \\
\hline
\end{tabular}


Each symbol that represents different types of activities was placed on a map of the hospital courtyard garden according to different types of users (patients, staff and visitors) on a piece of A4 paper (see Figure 5). The map of activities recorded for a period of 2 hours based on observation conducted from $3 \mathrm{pm}$ to $5 \mathrm{pm}$ is shown in Figure 5 . This mapping activity of 2 hours observations was continued for another 6 hours of observations to establish a complete set of mapping for one-day 8 hour observation period (see Figure 4)

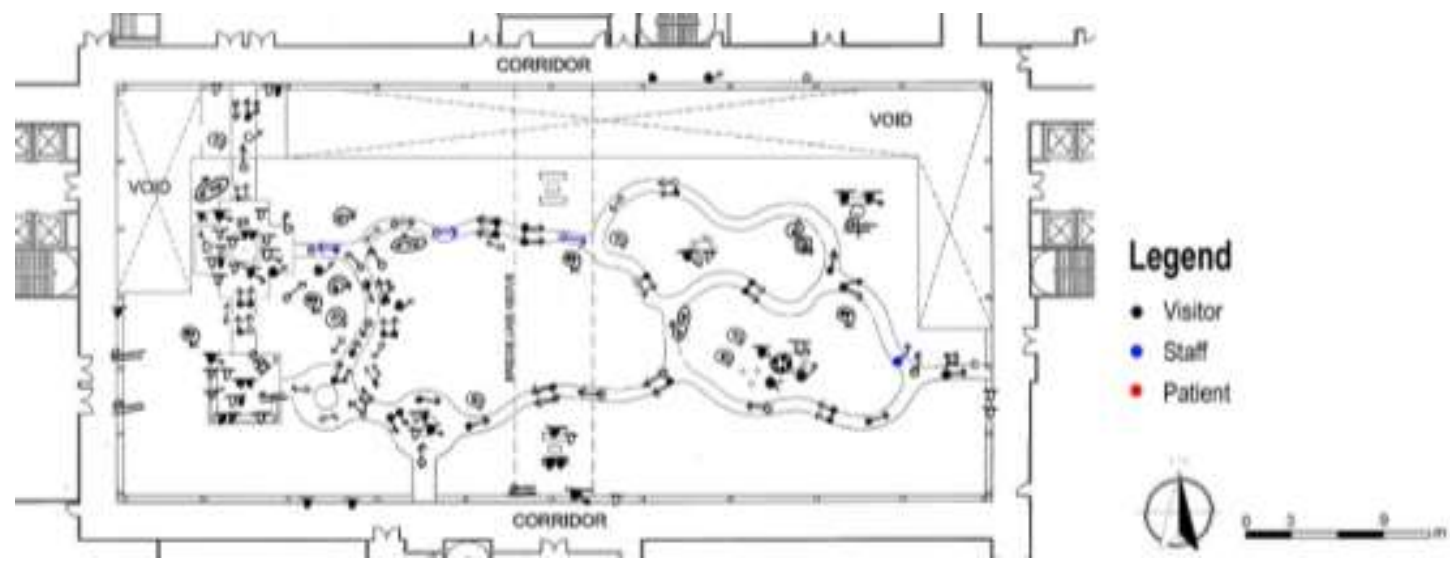

Fig. 5. A sample of mapping activity of 2-hour observation (Date: 5/3/2018 (Monday); Time: 3 pm - 5 pm)

\subsection{Analysis of mapping activities}

A complete set of data mapping for 8 hours of observation, including data gathered from video recording and a direct observation of all four consecutive days that were originally mapped by hand by the researcher, were then digitally re-coded and re-mapped into the GIS map system using ArcMap 10.4.1. The data for each user was transferred into a data attributes table in GIS and were coded according to the type of users, types of activities, gender and age groups (see Figure 6). This produced a rich and comprehensive database that allowed data to be visualised in a number of different ways, either as a combination of data for all four consecutive days or as a single day (weekday or weekend), or as data from a similar time of day (e.g. $9 \mathrm{am}$ to $11 \mathrm{am}$ or $3 \mathrm{pm}$ to $5 \mathrm{pm}$ ), or data taken during different weather conditions (e.g. breezy, sunny or cloudy days). These databases allowed for a comparison to be made of the space use patterns of the different types of users in the hospital courtyard garden with a different layer of data in order to understand the users' spatial relationship with the hospital courtyard garden and how they interacted with the various courtyard physical attributes and microclimatic conditions.

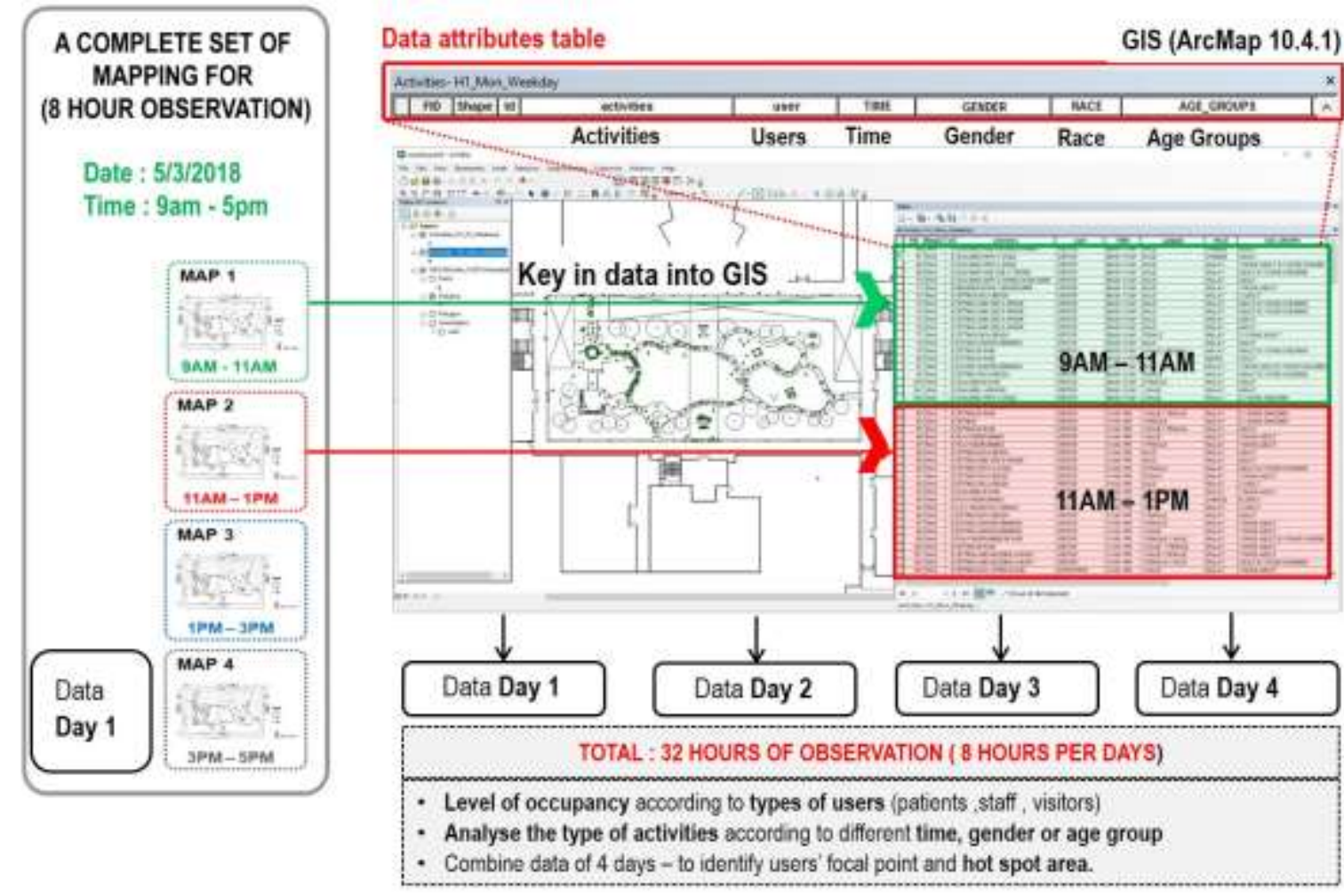

Fig. 6. Process of mapping and coding the data into GIS map system 


\subsection{Findings and Discussion}

\subsection{Types of activities}

Results of 8 hours observation showed that sitting, walking, standing, laying down, reading, eating, drinking and playing are the seven types of main activities found in this hospital courtyard garden out of about 30 specific activities observed during the observation which included both passive and active activities as shown in Table 1.

Figure 7 and Figure 8 show mapping activity which utilised GIS to visualise the activities in the courtyard garden of the hospital according to the type of users and the type of activities based on 8 hours observation during a weekday. From the observation, it was found that the hospital visitors had the highest level of occupancy of the $\mathrm{H} 1$ hospital courtyard garden, followed by the staff and then patients as indicated in Figure 7. These findings differ significantly in the way hospital staff use the outdoor space when compared to staff in healthcare buildings in other countries. For example, Shukor (2012) found that staff mostly uses outdoor gardens in acute care hospitals in Denmark compared to patients and visitors. The most frequent activities recorded among the staff included having lunch, relaxing and smoking. In contrast, another previous study conducted in California by Cooper Marcus and Barnes (1995) also reported that the greatest use of the outdoor garden is by staff followed by patients and visitors.
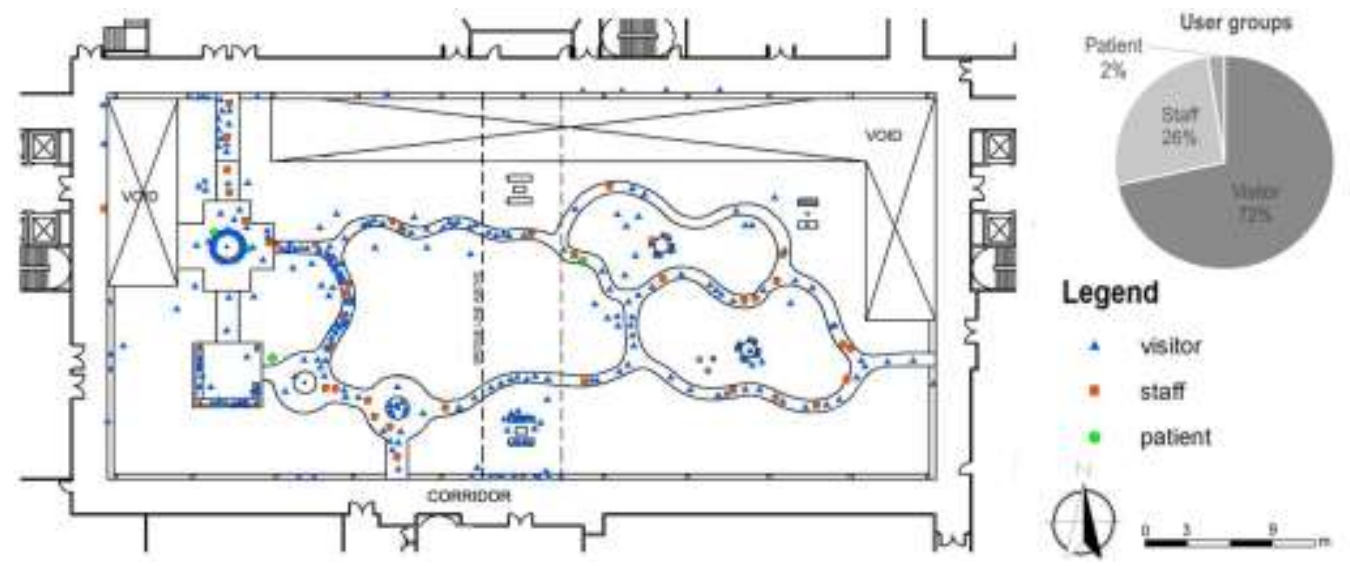

Fig. 7. A mapping activity by different type of users in hospitals on a weekday using GIS. (Date: 5/3/2018(Monday); Time: 9 am - 5 pm)

Figure 8 shows the mapping activity of an 8-hour weekday observation which mapped the activity according to different types of activities. The map indicates that the highest number of activities are walking followed by sitting, playing, eating/drinking, laying down, standing and reading a book/newspaper. Previous studies have reported that some of the main activities in the outdoor garden of hospital buildings include smoking (Cooper Marcus and Barnes, 1995; Shukor, 2012). However, it is interesting to note that smoking is not recorded in the courtyard garden of the Malaysian hospital $\mathrm{H} 1$ because the hospital policy did not allow smoking and vaping activities within the boundary of the hospital complex.
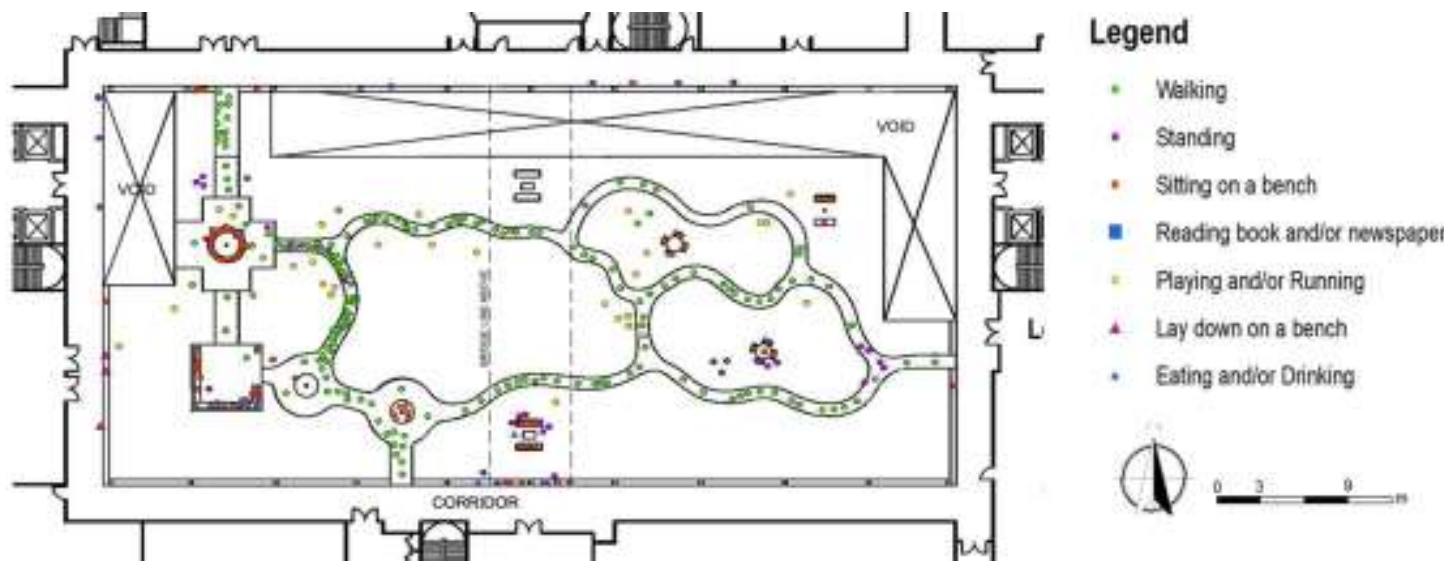

Fig. 8. A mapping activity by different type of activities in hospitals on a weekday using GIS (Date: 5/3/2018(Monday); Time: 9 am - 5 pm)

\subsection{Users' space use pattern}

Prior studies evaluating post occupancy in healthcare garden facilities noted that there is a strong relationship between the behaviour of users with the physical environment and opening hours (Cooper Marcus and Barnes, 1995; Cooper Marcus and Francis, 1998; Whitehouse et al., 2001; Sherman et al., 2005; Shukor, 2012). The opening hours of hospitals such as visiting hours, office hours and clinic opening hours significantly affect the rhythm of the users' occupancy in the hospital courtyard garden. Therefore, it is important to 
understand how this affects the occupancy of the different types of users at different times of the day and week. Figure 9 shows the opening hours of the hospital during the weekday and weekend in which there is a difference in users' space use pattern between two distinct periods, the weekend and weekdays.

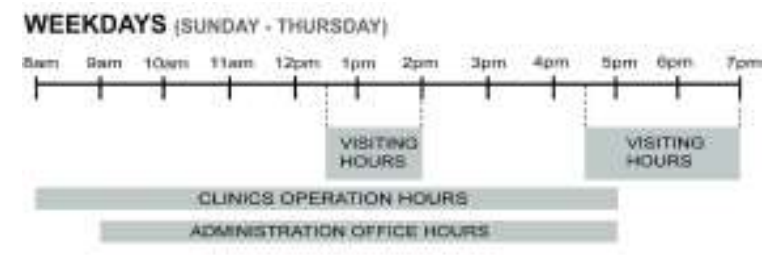

(a)

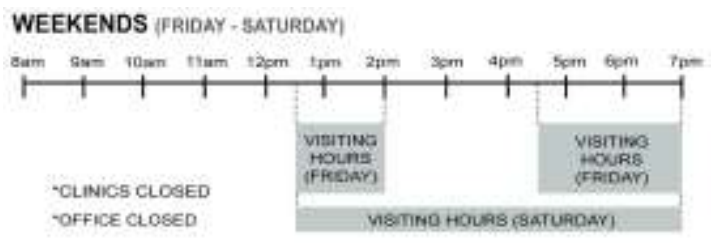

(b)

Fig. 9. (a) Opening hours of the $\mathrm{H} 1$ hospital during weekdays; (b) Opening hours of the $\mathrm{H} 1$ hospital during weekends

\subsection{Daily occupancy of different types of users during a weekday and a weekend.}

A total of 520 and 481 users were observed for 8 hours observation on a weekday (5/3/2018 - Monday) and a weekend (9/3/2018 Friday) on March 2018 from 9 am to $5 \mathrm{pm}$. The weather recorded during those days was cloudy and sunny with a temperature range of $27^{\circ} \mathrm{C}$ to $30^{\circ} \mathrm{C}$ in the morning $(9 \mathrm{am}-12 \mathrm{pm})$ and gradually increase from $30^{\circ} \mathrm{C}$ to $32^{\circ} \mathrm{C}$ in the afternoon $(12 \mathrm{pm}-3 \mathrm{pm})$. During late afternoon $(3 \mathrm{pm}-5 \mathrm{pm})$, the temperature gradually decreased from $32^{\circ} \mathrm{C}$ to $30^{\circ} \mathrm{C}$. The wind speed ranged from calm $(1.1 \mathrm{~km} / \mathrm{h})$ to breezy $(15.0 \mathrm{~km} / \mathrm{h})$ throughout those days. This study found that there is a significant difference in the density of the level of occupancy at different times of the day: morning, afternoon and late afternoon. Figure 10 (a) and (b) shows the level of occupancy of different types of users during a weekday and a weekend. Similar types of activities were recorded within each of three different groups during weekday and weekend as shown in Figure 11 (a) and (b). For visitors, activities included sitting on a bench, sitting in pairs and/or in a group, walking around, walking to pass through, eating, reading, playing and laying down on a bench. The activity recorded among staff included walking to pass through, sitting on a bench, standing and talking on a phone. The activity among patients included sitting on a bench, walking around in pairs, eating, reading, sitting in pairs and in a group.

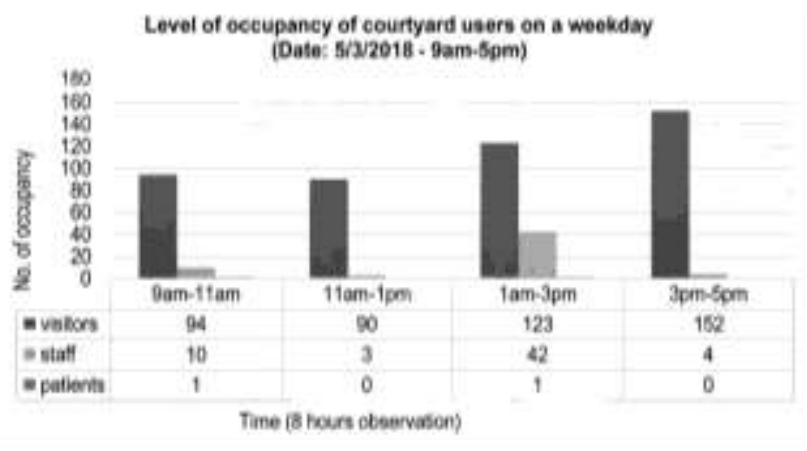

(a)

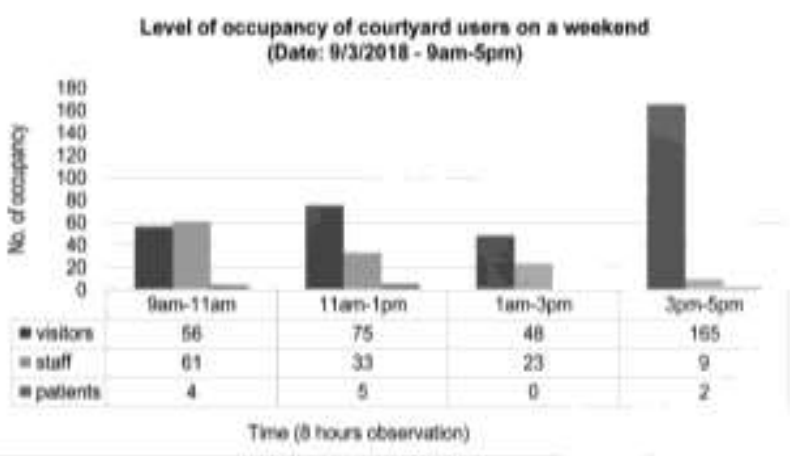

(b)

Fig. 10. (a) Level of occupancy of different types of users on a weekday; (b) Level of occupancy of different types of users on a weekend

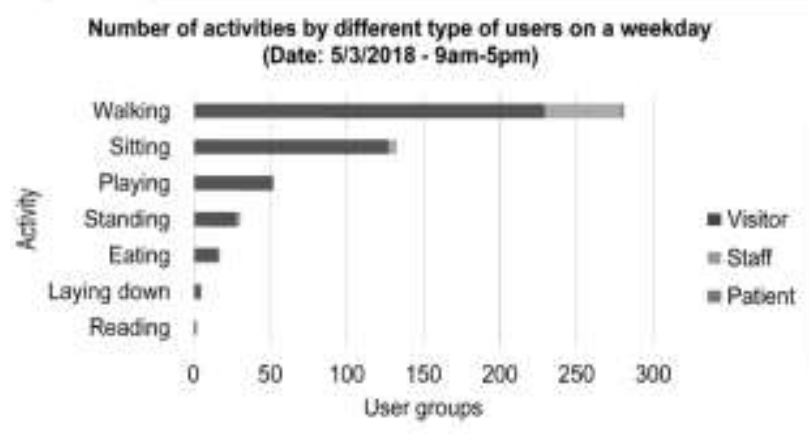

(a)

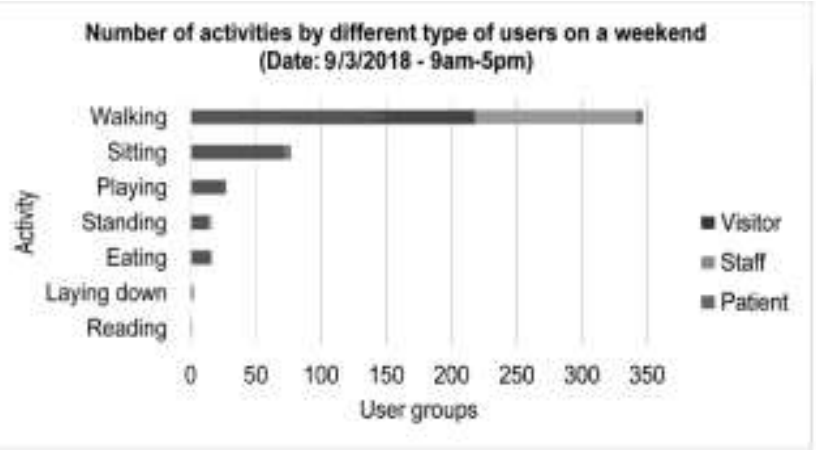

(b)

Fig. 11. (a) Number of activities by different types of users on a weekday; (b) Number of activities by different types of users on a weekend.

\subsubsection{Morning}

This study found that the occupancy of visitors in the weekday morning ( 9 am $-12 \mathrm{pm})$ was higher compared to that found for a weekend morning. On a weekday morning, the courtyard garden is mostly occupied by visitors who are waiting for their family or friends attending 
an appointment at the hospital's clinic. Direct observation revealed that in the morning, the pergola shaded sitting area and the concrete bench around the water fountain (located adjacent to the entrance of the courtyard garden) were the main focal points used by the visitors. The main activities recorded for visitors in the weekday morning included sitting on a bench and using a phone, sitting with a child, sitting in a pair or group, eating and reading the newspaper. On the weekend, very few visitors were found to spend time in the courtyard during the morning time because most of the clinics in the hospital are closed as they opened on weekdays only. During the weekend, those found in the courtyard at this time included those who stayed overnight in the visitors' rest house located next to the courtyard garden; such visitors often decided to sit at a more secluded sitting area to do the contemplative activity. In addition to the physical characteristics of the courtyard garden and the hospitals' opening hours, the microclimatic conditions were also found to influence the way users occupied and interacted with the courtyard garden. Observations taken during late morning (11 am - $12 \mathrm{pm})$ for both weekday and weekend periods showed that most people decided to sit at shaded sitting area located underneath a large canopy trees, the pergola shaded sitting area the bridge and the benches at the periphery of the courtyard garden (see Figure 12 (a) - (c)).

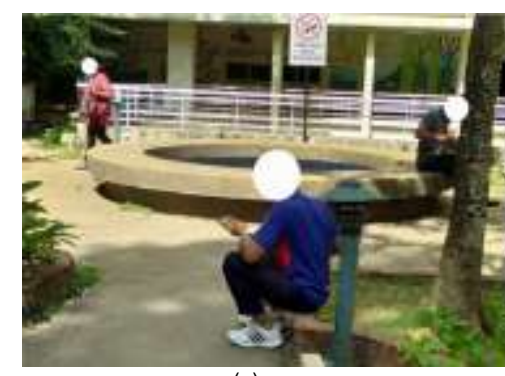

(a)

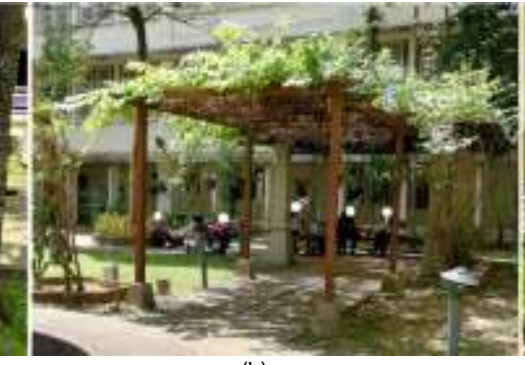

(b)

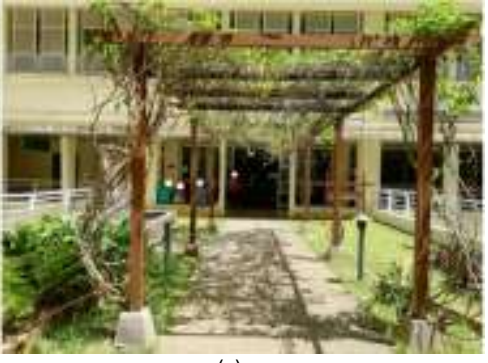

(c)

Fig. 12. (a) An adult male sitting on the bench and reading newspapers under a dapple shade while waiting for visiting time. A young adult male sitting at the edge of the planter box under shaded canopy tree while waiting to visit his friend in the ward (Weekend; Time: 11.40 am); (b) An outpatient sits under the shaded area near to pergola shaded sitting area while accompanied by his relatives. An elderly couple sitting and having a lunch under the pergola sitting area while an adult man sitting on a bench and use a phone (Weekday; Time: $11.58 \mathrm{am}$ ); (c) An adult couple sitting and adult Indian women (visitors) sitting on the benches at the periphery of the courtyard garden adjacent to the cafeteria entrances (Weekday; Time: 11.58 am).

On a weekday morning ( $9 \mathrm{am}-12 \mathrm{pm})$, several outpatients were found to use the courtyard to either pass through it or spend time sitting under the shaded pergola area. However, no hospitalised patients were found in the courtyard during a weekday morning time. Surprisingly, this current study found that the number of inpatients spending time in the courtyard garden during a weekend morning was higher compared to a weekday morning. Several wheelchair inpatients were accompanied by their relatives to pass through the courtyard garden during a weekend day. In addition, several inpatients who were physically independent and unbounded in bed were observed to have a short walk with their friend in the courtyard garden. It was observed that some of the inpatients decided to sit in the morning sunlight at the bench around the water fountain while others choose to sit at a dapple shaded sitting area such as the pergola sitting area (See Figure $13(\mathrm{a})-(\mathrm{c}))$.

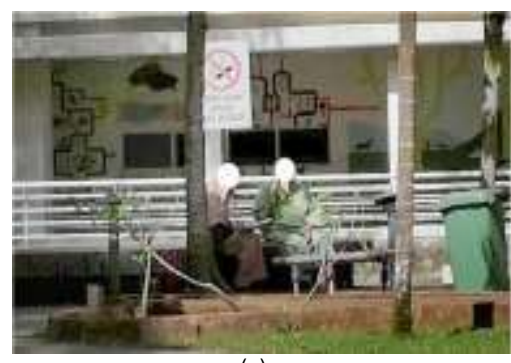

(a)

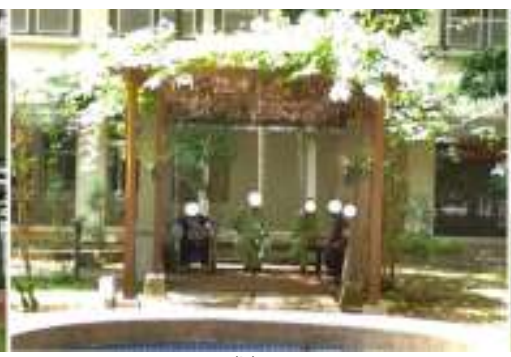

(b)

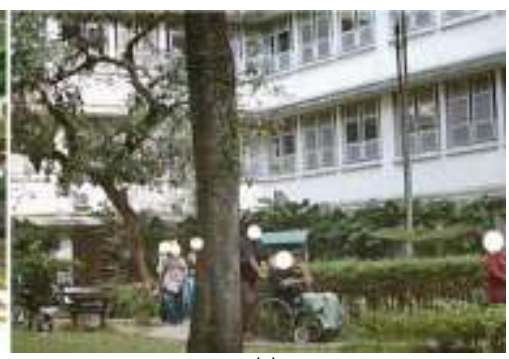

(c)

Fig. 13. (a) An Indian female inpatient sitting on the bench around the water fountain while having some snack (Weekend; Time: 10.38 am); (b) Two Indian male inpatients and one Indian female outpatient were observed to spend time sitting under the shaded pergola, mingle around and talking with other visitors (Weekend; Time: $11.20 \mathrm{am}$ ); (c) A Malay inpatient sitting in a wheelchair at a shaded area spending time in the courtyard garden with his family member (Weekend; Time: $10.05 \mathrm{am}$ ).

During the weekday morning, in addition to the visitors and patients, very few administrative and medical staff (doctors and nurses) were observed to walk through the garden despite the fact that this is the busiest time when the medical staff examine both inpatients in the wards and outpatients in the clinic. However, during the weekend, no hospital administration staff were found to spend time in the courtyard garden because they do not work on the weekends. Surprisingly, a higher number of medical staff (doctors and nurses) were found to pass through the garden to go to another hospital department during the weekend morning compared to a weekday morning. 


\subsubsection{Afternoon}

A higher number of visitors were found to spend time in the courtyard compared to staff and patients during the afternoon on both a weekday and a weekend day. However, the number of visitors spending time in the courtyard garden during the afternoon (12 pm - 3 $\mathrm{pm}$ ) were lower compared to the morning and late afternoon of the same day. At mid-day time, most visitors were found sitting in a shaded area in the courtyard garden. During lunchtime, it was also observed that some visitors had brought a packed lunch from the cafeteria to eat in the shaded sitting areas in the courtyard garden. Similar space use patterns were found among visitors on both weekdays and weekends: once the visiting time began at $12.30 \mathrm{pm}$, most of them were observed to leave the courtyard garden to visit family members in the wards, leaving behind several groups of young children accompanied by family members to play in the courtyard garden.

During the weekday afternoon, several administrative staff and medical staff were found to pass through the garden to go to the cafeteria for their lunch. Although the administrative and medical staff are seen to pass through the courtyard garden, none were observed having lunch in the courtyard garden. This observation shows that more staff was found to use the courtyard garden on the weekend afternoon compared to a weekday (to pass through, either to go to another department or to the cafeteria). One of the main reasons for this observation is that the corridor which functions as the main hospital street was locked during weekends due to security reasons (see Figure 14 (a) and (b)). In addition to the visitors and staff, differences in the way hospitalised patients spent time in the courtyard garden were observed: few of them were found to spend time in the courtyard garden in the afternoon compared to the morning and late afternoon of both a week and a weekend day.

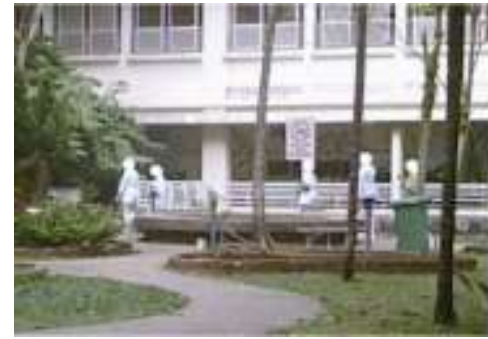

(a)

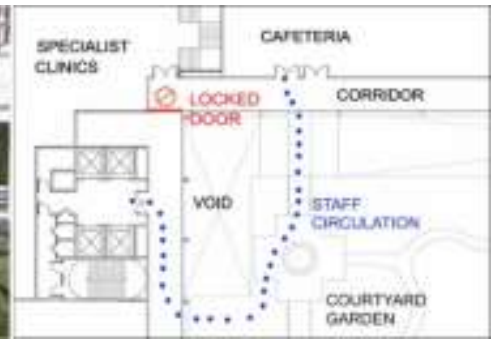

(b)

Fig. 14. (a) A group of nurses walk to pass through the courtyard garden to go to another hospital departments (Weekend; Time: 1.20 p.m.); (b) A map indicates the location of the locked door at the main hospital route and the circulation of the medical staff to pass through the courtyard garden during weekends.

\subsubsection{Late afternoon}

The first visiting time of the day ended at $2 \mathrm{pm}$ when the same visitors were observed to return to the courtyard garden to wait for the next visiting time of the day which begins at $4.30 \mathrm{pm}$. This study found that the highest occupancy in the courtyard garden among visitors was recorded between $3.30 \mathrm{pm}$ to $4.30 \mathrm{pm}$ on both the weekend and weekdays. Several family groups, waiting for patients' visiting hours, were observed to sit on a bench around the water fountain (see Figure 15(a)). Surprisingly, some new activities were found to take place in the courtyard at this time, including a young adult male laid down on a bench under the pergola shaded area while other family members were sitting and waiting for the next visiting time to start. At the same time, two adult males were found laid down for a nap on a bench at the periphery of the courtyard garden prior to visiting hours starting again (see Figure 15 (b)). Later, soon after the beginning of visiting hours at $4.30 \mathrm{pm}$, most of the visitors who had been waiting in the courtyard garden left to visit their family member(s) in the wards, and it was very rare to see any group of visitors staying in the courtyard garden after $4.30 \mathrm{pm}$. Similar such activity was also observed during the weekend late afternoon period.

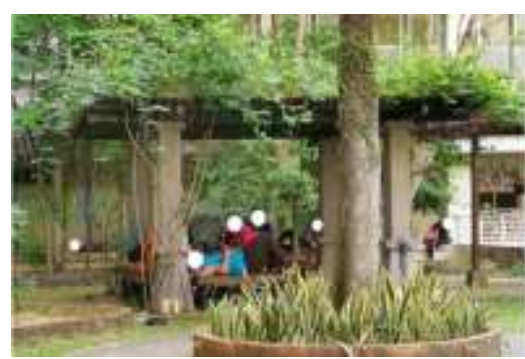

(a)

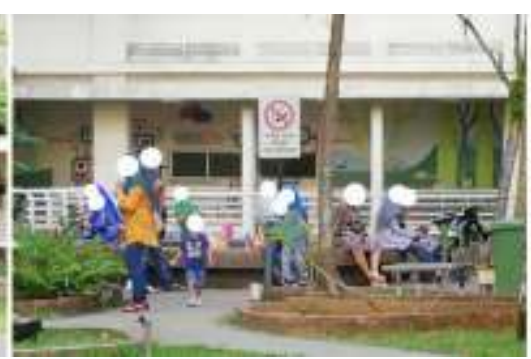

(b)

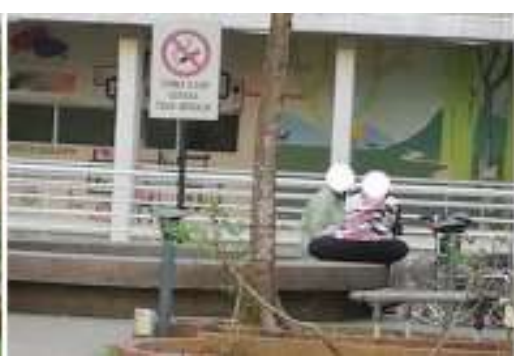

(c)

Fig. 15. (a) A group of visitors sitting on the benches around the water fountain (Weekend; Time: $4.12 \mathrm{pm}$ ); (b) One visitor was observed laying down on the benches under the pergola. Two people were observed laying down at the benches at the periphery of the courtyard garden. (Weekday; Time: $3.59 \mathrm{pm}$ ); (c) A inpatient sitting on the bench around the water fountain with his family member (Weekend; Time: $4.10 \mathrm{pm}$ ).

The observations show that a higher number of hospitalised patients were observed to spend time in the courtyard with their family or friends during the weekend late afternoon period compared to the late afternoon weekday period. Figure 15 (c) shows a male inpatient accompanied by his relative do a short walk around the courtyard garden during the weekday late afternoon. During the weekend late 
afternoon period, several wheelchair inpatients were observed to spend time in the courtyard moving around in the courtyard garden while others were found to sit on a bench around the water fountain accompanied by their relatives. However, very few staff were observed walking around the courtyard during the weekday late afternoon; further, only a few administration staff were seen to pass through the courtyard garden as the office hours ended at $5 \mathrm{pm}$.

\subsection{Implications of the Study}

The findings of this study have important implications to several audiences including the hospital provider, architects and landscape architects. For the hospital provider, they could use the findings of this research as a guide to improve their existing courtyard gardens by looking at how the users react and used the existing facilities in the hospital courtyard garden. These finding could also guide them to improve on any unsuccessful features within their garden so that it could enhance the social and well-being of the staff, patients and visitors. Designers (e.g. architects and landscape architects) could gain benefits from the results of the present study as it provides information to the designer about what works well in the site and how design is used and functions for the intended users. These findings could assist designers to critically think of their design approach, for example in terms of whether it leads to a well-utilised or underutilised courtyard garden. The architect could also learn from the results of successful and unsuccessful designs and planning of the hospital courtyard garden and use these findings as a guide to review, revise and update the design and planning approaches to create a more responsive and effective courtyard garden design for hospitals in Malaysia. Moreover, the landscape architect could also benefit from this finding as it graphically expresses how the users use and interact with the landscape elements in the courtyard garden. This could lead to improving the future landscape design for hospital courtyard gardens in the context of a hot and humid climate.

\subsection{Limitations of the Study and Future Research.}

Two limitations discovered during carrying out this study involved limitations in the observational method adopted here. Firstly, limitations in the process of identification of the sample among patients which involves both inpatient and outpatients. The current study was unable to identify outpatients because their appearance and clothing were similar to the visitors' clothing. The current study was therefore limited to focusing observation on inpatients (hospitalised patients) because they were easier to be identify by their ward uniform. Secondly, the current study only observed those who visited and spent time in the courtyard and at the periphery of the courtyard garden. Due to the limited numbers of observers and time constraints, this study was unable to observe those who used the courtyard for viewing either looking from the bridge located above the courtyard garden or those viewing the garden from the windows.

It is important to note that the discussion in this paper so far is limited to one case study of a large central courtyard hospital. This type of courtyard garden has its physical characteristics and design aspects which differ from other hospitals. Certainly, future discussion needs to be undertaken involving different courtyard design configurations to look at how differences in design configuration, physical conditions as well as microclimatic conditions of the site influences the space use patterns of the courtyard users.

Although the ongoing $\mathrm{PhD}$ study was able to collect environmental data (air temperature, air humidity and wind velocity) for a total periods of 32 hours observation (4 days), it should be kept in mind that this aspect was not discussed in detail here as the focus of this paper is limited to the discussion of the observational study which is to understand the activities and space use pattern of the different types of courtyard users in the courtyard garden of the hospital. Therefore, further research regarding how the microclimatic conditions of the site effects users' behavior and their comfort perception would be a worthwhile to investigate.

\subsection{Conclusion}

This paper presented the findings of the space use patterns among different types of hospital users (patients, staff and visitors) based on eight hours of on-site observation during a weekday and a weekend of the same week. The analyses of the observation data and the mapping activity in the courtyard garden revealed that the occupancy of the three groups of users is highly influenced by three key factors: the courtyard physical attributes, microclimatic conditions and the hospital opening hours. The results indicate that the vast majority of the users in the case study hospital ( $\mathrm{H} 1)$ courtyard garden were visitors (72\%), followed by the staff (26\%) and the patients $(5 \%)$. Nevertheless, it was observed in this study that during the weekday, a large number of the staff used the courtyard to pass through the garden (86\%) and only a very small number of the staff was found involved in a stationary activity (sitting $(7 \%)$, standing $(5 \%)$ and eating $(2 \%)$ compared to visitors and patients. During the weekend most of the staff used the courtyard to pass through the garden, and none of the other activities was recorded. This study also determined that more inpatients are likely to spend time in the courtyard garden during the weekends rather than weekdays. In addition, this study also revealed that the design features in the courtyard garden such as pergola shaded area and benches around the water fountain are the main points of attraction of the courtyard garden in $\mathrm{H} 1$ which is often occupied by both visitors and patients particularly during late afternoons ( $3 \mathrm{pm}-5 \mathrm{pm}$ ).

For this study, the dual data collection approach of video-based observation and direct observation, in addition to carrying out the mapping activity, proved to be very successful in acquiring complementary and reliable data. This study allowed for a clear understanding to be formed regarding the behaviour of different courtyard users over two distinct time periods, the weekend and weekdays. Moreover, this study also highlighted some of the practical and ethical challenges in conducting observations in hospital buildings in Malaysia and this contributes some insight into future studies on the relevant ethical aspects that need to be considered before undertaking this type of study. The limitation of this study is that it only focused on one typology of hospital courtyard design which is a large central courtyard configuration. Further research needs to be carried out to examine how the different users of other types of courtyard gardens in 
Malaysian hospitals behave in different courtyard settings and also to understand their perception, experiences and level of satisfaction regarding the hospital courtyard garden. This will allow for a comprehensive set of guidelines that integrate both the environmental and restorative roles of courtyard design to develop an effective and responsive courtyard design for a hospital in the context of a hot humid climate in Malaysia.

\section{Acknowledgements}

The authors would like to acknowledge the Ministry of Higher Education of Malaysia and the Islamic Science University Malaysia (USIM) for providing the financial support for the PhD study. We would also like to appreciate the director General of Health Malaysia for the permission to publish this paper. We would also like to express our gratitude to the hospital director of $\mathrm{H} 1$ hospital for their cooperation and granting permission to conduct the study at the case study hospital. Finally, thanks to those who have been involved directly or indirectly in assisting and supporting the preparation of this paper.

\section{References}

Almhafdy, A., Ibrahim, N., Ahmad, S.S. and Yahya, J. (2013a). Analysis of the Courtyard Functions and its Design Variants in the Malaysian Hospitals. Procedia-Social and Behavioral Sciences, 105, pp.171-182.

Almhafdy, A., Ibrahim, N., Ahmad, S.S. and Yahya, J. (2013b). Courtyard design variants and microclimate performance. Procedia-Social and Behavioral Sciences, 101, pp.170-180.

Almhafdy, A., Ahmad, S. S., \& Wan Salleh, W. M. (2014). Courtyard as a Microclimatic Modifier Experimental Study on Actual Site. Applied Mechanics \& Materials, (567).

Aripin, S. (2007). November. Healing Architecture: Daylight in hospital design. In Conference on Sustainable Building South East Asia, Vol. 5, p.7.

Bechtel, R.B., Marans, R., Michelson, W. (1987). Methods in Environmental and Behavioural Research. Van Nostrand Reinhold, New York.

Cooper Marcus, C. (2007). Healing gardens in hospitals. Interdisciplinary Design and Research e-Journal, 1(1), pp.1-27.

Cooper Marcus, C., and Barnes, M. (1995). Gardens in healthcare facilities: Uses, therapeutic benefits, and design recommendations. Concord, CA: Center for Health Design.

Cooper Marcus, C., Francis, C. (1998). People Places: Design Guidelines for Urban Open Space, 2nd ed. John Wiley \& Sons, Inc., Toronto.

Crow, G., \& Wiles, R. (2008). Managing anonymity and confidentiality in social research: The case of visual data in community research.

Gehl, J. (1987). Life Between Buildings: Using Public Space. Van Nostrand Reinhold, New York.

Ghazali, R. and Abbas, M. Y. (2012) 'Natural Environment in Paediatric Wards: Status and Implications', Procedia - Social and Behavioral Sciences, 68(December 2010), pp. 173-182

Goličnik, B., \& Thompson, C. W. (2010). Emerging relationships between design and use of urban park spaces. Landscape and Urban Planning, 94(1), 38-53.

Ittelson, W.H., Rivlin, L.G., Prohansky, H.M. (1970). The use of behavioural maps in environmental psychology. In: Prohansky, H.M., Ittelson, W.H., Rivlin, L.G. (Eds.), Environmental Psychology: Man and his Physical Setting. Holt, Rinehart \&Winston, New York, pp. 658-668.

Jamaludin, A. A., Hussein, H., \& Tahir, K. M. (2016). Resident's acceptance of internal courtyard buildings. In MATEC Web of Conferences (Vol. 66, p. 00098). EDP Sciences.

Jewitt, C., (2012). 'An introduction to using video for research', National Centre Research Method (NCRM).

Kawulich, B. B. (2005, May). Participant observation as a data collection method. In Forum Qualitative Sozialforschung/Forum: Qualitative Social Research (Vol. 6, No. 2).

Kubota, T., Zakaria, M. A., Abe, S., \& Toe, D. H. C. (2017). Thermal functions of internal courtyards in traditional Chinese shophouses in the hot-humid climate of Malaysia. Building and Environment, 112, 115-131.

Naderi, J.R. and Shin, W.H. (2008). Humane design for hospital landscapes: a case study in landscape architecture of a healing garden for nurses. Herd, 2(1), pp.82119.

Paine, R. (1984). Design Guidelines for Hospital Outdoor Spaces: Case Studies of Three Hospitals (Doctoral dissertation in Landscape Architecture, University of California, Berkeley).

Sadafi, N., Salleh, E., Haw, L. C., and Jaafar, Z. (2011). Evaluating thermal effects of the internal courtyard in a tropical terrace house by computational simulation. Energy and Buildings, 43(4), 887-893

Said, I. (2003) 'Garden as an Environmental Intervention in Healing Process of Hospitalised Children', Proceedings KUSTEM 2nd Annual Seminar on Sustainability Science and Management, Environment Détente: Quo Vadis Ecological Economics and Sciences, 6-7 May 2003, Awana Kijal Golf and Country Resort, Kemaman, Terengganu., pp. 1-11. 
Sh. Ahmad, S., Mat Som, N., Ong, S.H., Harith, Z.Y., and Othman, A.R. (2007). 'Daylighting in Courtyard hospital wards in Malaysia', in PAM Academic Journal, Kuala Lumpur, Yamagata, Vol 1, 1/2007, pp 97-117.

Sherman, S. A., Varni, J. W., Ulrich, R. S. and Malcarne, V. L. (2005). 'Post-occupancy evaluation of healing gardens in a paediatric cancer centre', Landscape and Urban Planning, 73(2-3), pp. 167-183.

Shukor, S.F.A. (2007). Design Characteristics of Healing Garden for Down's Syndrome Children in Malaysia (Master dissertation, Universiti Putra Malaysia).

Shukor, S.F.A. (2012). Restorative Green Outdoor Environment at Acute Care Hospitals. Case Studies in Denmark. Forest \& Landscape Research, (57-2012). (Doctoral dissertation, University of Copenhagen).

Toone, T. L. (2008). Effects of Healing Garden Use on Stress Experienced by Parents of Patients in a Pediatric Hospital (Master dissertation, Texas A \& M University).

Ulrich, R.S. (1984). View through a Window May Influence Recovery from Surgery. Source: Science, New Series, 224(4647), pp.420-421.

Verderber, S. and Reuman, D. (1987). Windows, Views, And Health Status in Hospital Therapeutic Environments. Journal of Architectural and Planning Research, 4(2), pp.120-133.

Watts, J. H. (2011). Ethical and practical challenges of participant observation in sensitive health research. International journal of social research methodology, 14(4), $301-312$.

Whitehouse, S., Varni, J. W., Seid, M., Cooper-MArcus, C., Ensberg, M. J., Jacobs, J. R. and Mehlenbeck, R. S. (2001). 'Evaluating a Children'S Hospital Garden Environment: Utilization and Consumer Satisfaction', Journal of Environmental Psychology, 21(3), pp. 301-314.

Whyte, W.H. (1980). The Social Life of Small Urban Spaces. Conservation Foundation, Washington, DC

Whyte, W.F. and Whyte, K.K. (1984). Learning from the Field: A guide from Experience. Beverly Hills, CA: Sage Publications.

Wiles, R., Prosser, J., Bagnoli, A., Clark, A., Davies, K., Holland, S. and Renold, E. (2008). Visual ethics: Ethical issues in visual research. 